\title{
Good and Poor Summary Writers' Strategies: The Case of Japanese High School EFL Learners
}

\author{
Makiko Kato \\ Graduate School of Languages and Linguistics, Sophia University, Tokyo, Japan
}

\begin{abstract}
Despite general belief about the importance of summary writing in foreign language education, and in the field of teaching Language for Academic Purposes (LAP) (e.g., Swales, 1981; 2000), it is shown that the development of this skill is one of the most difficult skills for learners (e.g., Brown and Day, 1980; Hirvela \& Du, 2013; Shi, 2012). This study is part of a larger project and its main purpose is to open the black box by exploring the relationship between performances of summary writing in English as a Foreign Language (EFL) and the strategies used for summary writing in EFL. A total of 74 Japanese high school EFL learners were asked to write a summary of one-third of approximately 230 word-long English passage and were subsequently asked to respond to the summary strategy inventory adapted partly from $\mathrm{Li}(2014)$. The data analysis showed that there was indeed a relationship between the quality of the students' summaries and the frequency of their implemented strategies. In this study, along with the results of in-depth analyses, various implications are offered to EFL education as well as future research studies.
\end{abstract}

Index Terms —writing a summary, EFL learners, summary writing strategies

\section{INTRODUCTION}

\section{A. The Nature of Summary Writing}

Summarizing a text is the integrated skill of reading and writing, and it is known as one of the most difficult skills for learners (Hirvela \& Du, 2013; Shi, 2012). It is also considered a highly complex, recursive reading-writing activity involving constraints that can impose an overwhelming cognitive load on students, thereby adversely affecting performance (Kirkland and Saunders, 1991).

Many of previous studies on strategies for summarizing a text drew insight from Kintsch and van Dijk's $(1978,1983)$ discussions of cognitive processes to derive the macrostructure of the original text. Kintsch and van Dijk's $(1978,1983)$ proposal of the summarizing process goes through three stages: deletion, generalization, and construction. Further, the stages are revised as following; comprehending individual propositions, establishing connections between propositions, identifying the constituent structure of a story, remembering the information in a story, selecting the information to be represented in a summary, and being concise and coherent (Brown \& Day, 1983; Kintsch \& Van Dijk, 1978, 1983). Following these six process rules, summary writers are required to reproduce a new text with their own words. To write a summary in a foreign language (FL), not only the proficiency in the FL (i.e., knowledge of grammar and vocabulary for reading and writing), but also the skill of summarizing the text are required to complete summary writing.

\section{B. Strategies for Summary Writing}

The use of strategy in learning L2 has been the purpose of a large body of research over the last 30 years (Plansky, 2011). However, little research has been conducted on summary writing strategies except for the reports by some researchers (e.g., Anderson, 1991; Brown \& Day, 1983; Johns \& Mayes, 1990; Keck, 2006, 2010; Li, 2014; Phakiti, 2003a; Shi, 2004), who reported that strategies for summarizing a text in L2 had differences depending on their FL proficiency or their depth of experience in writing. For instance, readers with higher proficiency use various strategies (Anderson, 1991; Phakiti, 2003a) and they are more global (Block, 1986; Carrell, 1989; Koda, 2005). On the contrary, those with lower proficiency use quite a few strategies than those with higher proficiency (Cohen, 1994) and they may use them inappropriately (Plakans, 2009), and they often use strategies such as copying and deleting (Brown and Day, 1983). In this way, various researchers have reported that the strategy used for writing a summary varies depending on the level of learner's EFL proficiency.

Within a few studies on strategies that EFL students reported using for summary writing, $\mathrm{Li}$ (2014) observed Chinese EFL summary writers in a university in China, and he reported that the importance of skills of reading and writing were different concerning the overall proficiency to write a summary, and writing strategies played a more critical role than reading strategies.

\section{RESEARCH QUESTIONS}

According to the previous studies on summary writing strategy, types and frequencies of strategies reported using by the EFL learners vary depending on the level of learners' EFL proficiency and the depth of their experience in academic writing. However, most participants in the previous studies were university-level EFL/ESL learners. Also, the studies 
on EFL summary writers' strategies were examined by conceptualizing the process of summary writing going through the linear stages of completing a summary, i.e., reading and writing, but in this research, four stages (i.e., before reading the text, while reading the text, after reading the text, and while writing a summary) summary writers go through will be asked, focusing on Japanese high school students of mixed levels of EFL proficiency. The common point between the groups is that they had never written a summary from the source text in English. The following two research questions are stated regarding the relationship between their summary performances and strategies they reported using during the four stages of writing a summary.

RQ1. What kinds of strategies do good / poor summary writers tend to use?

RQ2. Is there any difference in the frequency of strategy use between the levels of summary performances?

RQ3. What factors affect summary performances?

\section{METHODOLOGY}

\section{A. Participants}

A total of 74 participants in this study were in the 2nd grade at a National Technical College in Japan, and $90 \%$ of participants were boys, and only $10 \%$ of them were girls. They have three English classes a week, and their English proficiency ranges between beginner to intermediate. For instance, some students have a score of 750 in TOEIC, and others seem to struggle to keep up with English classes. However, all students are unfamiliar with writing a summary in English.

\section{B. Raters}

Three raters who had EFL teaching experiences assessed all students' summaries respectively. Their English proficiency was upper intermediate level. For the sake of consistency, a consensus among three raters was set to exclude students who had not written anything or written just one sentence. As a result, 74 students finally remained as the participants of this study. The internal-consistency reliability measured by the Cronbach alpha was as follows: $\alpha=$ 0.76 for Main Idea Coverage; $\alpha=0.83$ for Integration; $\alpha=0.84$ for Language Use; and $\alpha=0.83$ for Source Use.

\section{Tasks}

All students received worksheets with approximately 230-word English text (Appendix A). This text is adapted from the section of reading comprehension of the EIKEN test, Japan's leading English proficiency assessment, at the grade of pre-2. All students were asked to write a summary in English with permission to see the English text within 30 minutes.

\section{Rubrics}

A scoring rubric to evaluate participants' summary scripts was adopted from Li (2014) (Appendix B). The rubric consisted of four components addressing different aspects of summarization abilities: Main Idea Coverage, Integration, Language Use, and Source Use. The can-do lists of each category were established, and the scores from zero to five were categorized as in Appendix B.

\section{E. Questionnaires}

The questionnaire consisted of the items asking if summary writers used the strategies at each stage of writing a summary; before reading the text, while reading the text, after reading the text, and while writing a summary (See Appendix C in detail). Each question was carefully selected from Li (2014), which students can easily imagine the concept. Besides, they were asked to answer the open-ended questions on the task of summary writing because it was their first time to write a summary.

\section{F. Data Collection and Data Analysis}

Before starting the data collection, all students were given a quick lecture on how to write a summary in English based on an example prepared by the present author. The instruction emphasized that they write a summary, which is short but detailed for the readers who have not read the source text to help them understand the main idea, that they do not copy any sentences directly from the text but paraphrase them, and that they place the main idea of the source text in the first sentence of the summary as a topic sentence. Subsequently, the teacher distributed a worksheet to students, asking them to write a summary for 30 minutes. They were allowed to look at the source text while they were writing a summary. After they finished writing a summary, they answered the questionnaire including items asking if summary writers used the strategies at each of the four stages to write a summary.

All the data collected by the questionnaire and writing a summary were analyzed using IBM SPSS statistics version 23.0. To observe the relationship between their strategy use and the quality of their produced summary, whole students were first divided into two levels of relatively higher and lower based on the ranking of the overall performance of their summary products. Second, strategies students in each group frequently used were chosen to examine what affected their performances.

\section{RESUltS AND DisCUSSION}


Given their summary performances, Table I shows that performances on students' summary were under the half scores of five full points in all evaluation items, and finding main ideas (Mean = 1.60, S.D. $=1.07$ ) seems to be difficult compared with other skills. Meanwhile, the score of Language Use (Mean = 2.14, S.D. $=1.28$ ) refers to the skill of choosing appropriate grammar and words were higher than any other item. The score overall was $7.64($ S.D. $=4.65)$, and the best score was 18.33 .

TABLE I.

RESUlT OF DESCRIPTIVE STATISTICS OF ALL 74 STUDENTS' SUMMARY PERFORMANCES

\begin{tabular}{lllll}
\hline & Mean & S.D. & Max. & Min. \\
\cline { 2 - 5 } Main Idea Coverage (5.00) & 1.60 & 1.07 & 4.67 & 0.00 \\
Integration (5.00) & 2.02 & 1.42 & 4.67 & 0.00 \\
Language Use (5.00) & 2.14 & 1.28 & 5.00 & 0.00 \\
Source Use (5.00) & 1.88 & 1.25 & 4.67 & 0.00 \\
Overall (20.00) & 7.64 & 4.65 & 18.33 & 0.00 \\
\hline
\end{tabular}

All students were divided into the top 37 and low 37 students by their overall scores. Tables II and III show that the mean of top 37 students was 11.36 (S.D. $=2.45)$ and that in the low proficiency group was 3.93 (S.D. = 3.08). Students in the high proficiency group seem to struggle to find main ideas (Mean $=2.32$, S.D. $=1.04$ ) because the score of Main Idea Coverage was lower than any other categories. However, the mean score of Integration (i.e., the skill of rearranging the order of the statements logically and demonstrating the global interpretation of the source text) was higher than any other evaluation item (Mean $=3.19$, S.D $=0.81)$, while that in the low proficiency group was lower than any other evaluation item (Mean $=0.86$, S.D. $=0.79)$.

TABLE II.

\begin{tabular}{lllll} 
RESULT OF DESCRIPTIVE STATISTICS OF 37 & \multicolumn{4}{l}{ HIGH PROFICIENCY GROUP STUDENTS' SUMMARY PERFORMANCES } \\
\hline & \multicolumn{4}{l}{ Students in the high proficiency group (n=37) } \\
\cline { 2 - 5 } & Mean & S.D. & Max. & Min. \\
Main Idea Coverage (5.00) & 2.32 & 1.04 & 4.67 & 0.67 \\
Integration (5.00) & 3.19 & 0.81 & 4.67 & 1.67 \\
Language Use (5.00) & 3.08 & 0.65 & 5.00 & 1.67 \\
Source Use (5.00) & 2.77 & 0.87 & 4.67 & 0.67 \\
Total (20.00) & 11.36 & 2.45 & 18.33 & 8.00 \\
\hline
\end{tabular}

TABLE III.

RESULT OF DESCRIPTIVE STATISTICS OF 37 LOW PROFICIENCY GROUP STUDENTS' SUMMARY PERFORMANCES Students in the low proficiency group $(\mathrm{n}=37)$

Main Idea Coverage (5.00) Integration (5.00) Language Use (5.00) Source Use (5.00) Total (20.00)

\begin{tabular}{llll} 
Mean & S.D. & Max. & Min. \\
\hline 0.93 & 0.60 & 2.00 & 0.00 \\
0.86 & 0.79 & 2.00 & 0.00 \\
1.19 & 1.04 & 3.00 & 0.00 \\
0.99 & 0.89 & 2.67 & 0.00 \\
3.93 & 3.08 & 7.67 & 0.00 \\
\hline
\end{tabular}

Table IV presents the descriptive statistics of the strategy they used in the four stages, and they tend to use various strategies in the stage of 'before-reading' (Mean = 3.55, S.D. = 1.11), but only two items like Q1 (You understand the task of summary writing) and Q2 (You understand the meaning of the text's title) were set, while a total of 15 items were set in the stage of 'while-reading', four items were in the stage of 'after-reading', and nine items were set in the stage of 'while-writing'. Given the stage of 'after-reading' (Mean = 1.94, S.D. = 0.99), they do not seem to use various strategies, but instead, they seem to use more strategies in the stages of 'while-reading' $($ Mean $=3.00$, S.D. $=0.78)$ and in 'while-writing' (Mean = 2.60, S.D. $=0.82$ ) than in 'before-reading' and 'after-reading'.

TABLE IV.

RESULT OF DESCRIPTIVE STATISTICS OF STRATEGY USED FOR SUMMARY WRITINGS IN THE FOUR STAGES

\begin{tabular}{|c|c|c|c|c|}
\hline & \multicolumn{4}{|c|}{ All students $(\mathrm{n}=72)$} \\
\hline & Mean & S.D. & Max. & Min. \\
\hline Before-reading ( 2 items) & 3.55 & 1.11 & 5.00 & 0.00 \\
\hline While reading (15bitems) & 3.00 & 0.78 & 5.00 & 0.00 \\
\hline After-reading (4 items) & 1.94 & 0.99 & 5.00 & 0.00 \\
\hline While-writing (9 items) & 2.60 & 0.82 & 4.56 & 0.00 \\
\hline
\end{tabular}

Given the relationship between their summary performances and the frequency of strategy use in the four stages, Table V shows the differences between the strategies the students in each group used in each stage, and students in the high proficiency group used more strategies than those in the low proficiency group in all stages. Statistically, there were no significant differences in the frequency of strategy use between the groups in the stage of 'before-reading' and 'after-reading', but in the stage of 'while-reading', $t(72)=2.75, p<.01$, and in 'while-writing', $t(72)=2.92, p<.01$. In this paper, from here, two stages of 'while-reading' and 'while-writing' will be focused to observe. 
TABLE V.

MOST FREQUENTLY USED STRATEGIES FOR SUMMARY WRITING IN THE FOUR STAGES OF EACH LEVEL

\begin{tabular}{lllllllll}
\hline & \multicolumn{3}{c}{ High proficiency group students $(\mathrm{n}=37)$} & \multicolumn{3}{c}{ Low proficiency group students $(\mathrm{n}=37)$} \\
& Mean & S.D. & Max. & Min. & Mean & S.D. & Max. & Min. \\
\cline { 2 - 8 } Before-reading & 3.65 & 1.22 & 5.00 & 0.00 & 3.45 & 0.99 & 5.00 & 1.00 \\
While-reading & 3.23 & 0.85 & 5.00 & 0.00 & 2.75 & 0.63 & 3.73 \\
After-reading & 2.05 & 1.10 & 5.00 & 0.00 & 1.82 & 0.85 & 3.75 & 0.00 \\
While-writing & 2.86 & 0.65 & 4.56 & 1.00 & 2.33 & 0.88 & 3.89 & 0.00 \\
\hline
\end{tabular}

To examine what kinds of strategies the students in each group used when they read and write (RQ1) and how different was the frequency of strategy use between the groups (RQ2), five strategies the students reported using the most in the stage of 'while-reading' and 'while-writing' were raised in Table VI. Interestingly, students in both groups used same strategies the most, and this finding is different from the view by some references (Anderson, 1991; Block, 1986; Brown \& Day, 1983; Carrell 1989; Cohen 1994; Koda, 2005; Phakiti, 2003a). However, as shown in Table VII, though most strategies which reported as the most used strategies (i.e., those in Table VI) were used the most frequently by students in both groups, the frequency of strategy use was significantly different between groups (See Table VII in detail). This finding is the same as Cohen (1994).

Some researchers (e.g., Choy \& Lee, 2012; Johns, 1985; Keck, 2006; Wichadee, 2013; Winograd, 1984) highlight that the experiences and practicing of writing summaries influence writers' summary performances, and all the students in this study perhaps could not know the effective strategies for writing an English summary because they all had never written English summary. In any case, among the students in this study, those who wrote an excellent summary used the strategies more frequently than those who wrote a poor summary.

To investigate the factors affecting summary performances (RQ3), each group, i.e., the high and low proficiency groups, was divided moreover into half; top 19 students and low 18 students on each. Table VIII shows the descriptive statistics of each group, and Table IX shows the correlation between the frequency of strategy use and their performance of summaries. According to Table IX, there was a relationship between them in the low proficiency group (i.e., between 19 higher students and 18 lower students in the low proficiency group): For reading strategy of Q8 (You read while paying attention to the meaning of the words or phrases in the text), $r=.33, p<.01$; for reading strategy of Q4 (You read while confirming the understanding of the text), $r=.34, p<.01$; for writing strategy of Q23 (You wrote a summary in your own words after selecting some parts from the English text), $r=.47, p<.01$; and for writing strategy of Q30 (You compared the summary you wrote with the original text), $r=.42, p<.01$. While there were negative correlations between them in the high proficiency group (i.e., between 19 higher students and 18 lower students in the high proficiency group): For reading strategy of Q12, $r=-.02$, n.s., for writing strategy of Q23, $r=-.06$, n.s.; and for writing strategy of Q30, $r=-.002$, n.s.

TABLE VI.

MOST USED FIVE STRATEGIES IN WHILE READING AND WRITING

\begin{tabular}{|c|c|c|c|c|c|c|c|c|c|}
\hline & \multirow[b]{2}{*}{ Strategies the students used the most in while-reading } & \multicolumn{4}{|c|}{$\begin{array}{l}\text { Students in the high proficiency } \\
\text { group }(n=37)\end{array}$} & \multicolumn{4}{|c|}{$\begin{array}{l}\text { Students in the low proficiency } \\
\text { group }(\mathrm{n}=37)\end{array}$} \\
\hline & & $\begin{array}{l}\text { Mea } \\
\mathrm{n}\end{array}$ & S.D. & Max. & Min. & $\begin{array}{l}\text { Mea } \\
\mathrm{n}\end{array}$ & S.D. & Max. & Min. \\
\hline Q3. & You read while guessing the approximate meaning. & 4.08 & 1.14 & 5.00 & 0.00 & 3.54 & 1.02 & 5.00 & 1.00 \\
\hline Q6. & $\begin{array}{l}\text { You read while predicting the meaning of unknown words } \\
\text { and phrases. }\end{array}$ & 3.86 & 1.03 & 5.00 & 0.00 & 3.30 & 1.02 & 5.00 & 1.00 \\
\hline Q12. & $\begin{array}{l}\text { If you could not understand English sentences, you read } \\
\text { them again. }\end{array}$ & 3.86 & 1.29 & 5.00 & 0.00 & 3.16 & 1.30 & 5.00 & 0.00 \\
\hline Q13. & $\begin{array}{l}\text { You read while considering the knowledge of the text } \\
\text { content you already had. }\end{array}$ & 3.81 & 1.13 & 5.00 & 0.00 & 3.14 & 1.29 & 5.00 & 0.00 \\
\hline \multirow[t]{3}{*}{ Q 4.} & You read while confirming the understanding of the text. & 3.73 & 1.19 & 5.00 & 0.00 & 2.89 & 1.29 & 5.00 & 0.00 \\
\hline & & \multicolumn{4}{|c|}{$\begin{array}{l}\text { Students in the high proficiency } \\
\text { group }(n=37)\end{array}$} & \multicolumn{4}{|c|}{$\begin{array}{l}\text { Students in the low proficiency } \\
\text { group }(n=37)\end{array}$} \\
\hline & Strategies the students used the most in while-writing & $\begin{array}{l}\text { Mea } \\
\mathrm{n}\end{array}$ & S.D. & Max. & Min. & $\begin{array}{l}\text { Mea } \\
\mathrm{n}\end{array}$ & S.D. & Max. & Min. \\
\hline Q29. & $\begin{array}{l}\text { You looked over the English text to catch some } \\
\text { information to be used for writing a summary. }\end{array}$ & 3.86 & 1.00 & 5.00 & 1.00 & 2.97 & 1.38 & 5.00 & 0.00 \\
\hline Q28. & $\begin{array}{l}\text { You wrote while looking over the specific phrases in the } \\
\text { English text to be used for writing a summary. }\end{array}$ & 3.70 & 1.05 & 5.00 & 1.00 & 2.95 & 1.43 & 5.00 & 0.00 \\
\hline Q23. & $\begin{array}{l}\text { You wrote a summary in your own words after selecting } \\
\text { some parts from the English text. }\end{array}$ & 3.70 & 1.08 & 5.00 & 1.00 & 2.62 & 1.40 & 5.00 & 0.00 \\
\hline Q30. & $\begin{array}{l}\text { You compared the summary you wrote with the original } \\
\text { text. }\end{array}$ & 2.97 & 1.36 & 5.00 & 1.00 & 2.35 & 1.23 & 5.00 & 0.00 \\
\hline Q26. & $\begin{array}{l}\text { You wrote a summary in Japanese using the diagrams and } \\
\text { tables summarized the English text, and translated it into } \\
\text { English. }\end{array}$ & 1.57 & 1.07 & 4.00 & 1.00 & 1.57 & 1.21 & 5.00 & 0.00 \\
\hline
\end{tabular}


TABLE VII.

T-Test Of The Largest Five Strategies Which Has Gaps Of The Frequency Of Strategy Use Between The Performances Of Each LEVEL

\begin{tabular}{|c|c|c|c|}
\hline & Strategy contents of the most used five strategies in while-reading $(n=74)$ & $t$ & $r$. \\
\hline Q 4. & You read while confirming the understanding of the text. & $2.90 * *$ & 8.54 \\
\hline Q 8. & You read while paying attention to the meaning of the words or phrases in the text. & $2.42 *$ & 8.54 \\
\hline Q12. & If you could not understand English sentences, you read them again. & $2.33 *$ & 8.54 \\
\hline Q13. & You read while considering the knowledge of the text content you already had. & $2.40 *$ & 8.54 \\
\hline Q 6. & $\begin{array}{l}\text { You read while predicting the meaning of unknown words and phrases. } \\
\text { Strategy contents of the most used five strategies in while-writing }(n=74)\end{array}$ & $2.34 *$ & 8.54 \\
\hline Q23. & You wrote a summary in your own words after selecting some parts from the English text. & $3.72 * * *$ & 8.54 \\
\hline Q29. & You looked over the English text to catch some information to be used for writing a summary. & $3.17 * *$ & 8.54 \\
\hline Q28. & You wrote while looking over the specific phrases in the English text to be used for writing a summary. & $2.59^{*}$ & 8.54 \\
\hline Q30. & You compared the summary you wrote with the original text. & $2.06^{*}$ & 8.54 \\
\hline Q26. & $\begin{array}{l}\text { You wrote a summary in Japanese using the diagrams and tables summarized the English text, and } \\
\text { translated it into English. }\end{array}$ & 0.00 & 0.00 \\
\hline
\end{tabular}

TABLE VIII.

RESULT OF DESCRIPTIVE STATISTICS OF SUMMARY PERFORMANCES IN EACH GROUP

Students in the high proficiency group $(\mathrm{n}=37)$

\begin{tabular}{|c|c|c|c|c|c|c|c|c|}
\hline \multirow[b]{3}{*}{ Main Idea Coverage (5.00) } & \multicolumn{8}{|c|}{ Students in the high proficiency group $(n=37)$} \\
\hline & Mean & S.D. & Max. & Min. & Mean & S.D. & Max. & Min. \\
\hline & 2.84 & 1.10 & 4.67 & 1.13 & 1.76 & 0.61 & 2.67 & 0.67 \\
\hline Integration (5.00) & 3.75 & 0.63 & 4.67 & 2.33 & 2.59 & 0.48 & 3.67 & 1.67 \\
\hline Language Use (5.00) & 3.32 & 0.58 & 5.00 & 2.33 & 2.83 & 0.64 & 4.33 & 1.67 \\
\hline Source Use (5.00) & 3.25 & 0.75 & 4.67 & 1.67 & 2.28 & 0.67 & 3.33 & 0.67 \\
\hline \multirow[t]{4}{*}{ Total $(20.00)$} & 13.11 & 2.16 & 18.33 & 10.67 & 9.52 & 0.87 & 10.67 & 8.00 \\
\hline & \multicolumn{8}{|c|}{ Students in the low proficiency group $(n=37)$} \\
\hline & \multicolumn{4}{|c|}{ Higher students in the low proficiency group $(n=19)$} & \multicolumn{4}{|c|}{ Lower students in the low proficiency group $(\mathrm{n}=18)$} \\
\hline & Mean & S.D. & Max. & Min. & Mean & S.D. & Max. & Min. \\
\hline Main Idea Coverage (5.00) & 1.33 & 0.29 & 2.00 & 1.00 & 0.50 & 0.54 & 2.00 & 0.00 \\
\hline Integration (5.00) & 1.51 & 0.45 & 2.00 & 0.67 & 0.17 & 0.35 & 1.33 & 0.00 \\
\hline Language Use (5.00) & 2.07 & 0.57 & 3.00 & 1.00 & 0.26 & 0.41 & 1.67 & 0.00 \\
\hline Source Use (5.00) & 1.77 & 0.46 & 2.67 & 1.33 & 0.17 & 0.24 & 0.67 & 0.00 \\
\hline Total (20.00) & 6.70 & 1.05 & 7.67 & 4.67 & 1.00 & 1.12 & 4.33 & 0.00 \\
\hline
\end{tabular}

TABLE IX.

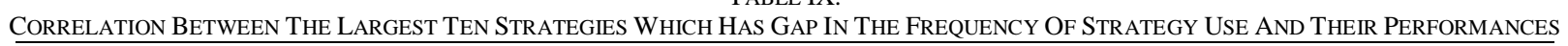

\begin{tabular}{|c|c|c|c|c|c|c|c|c|c|c|}
\hline & \multicolumn{5}{|c|}{ While-reading } & \multicolumn{5}{|c|}{ While-writing } \\
\hline & Q4. & Q6. & Q8. & Q12. & Q13. & Q23. & Q26. & Q28. & Q29. & Q30. \\
\hline All $(n=74)$ & $.37 * * *$ & $.31 * *$ & $.37 * * *$ & $.27 *$ & $.31 * *$ & $.47 * * *$ & .03 & $.29 * *$ & $.33 * *$ & $.31 * *$ \\
\hline Higher $(n=37)$ & .01 & .10 & .20 & -.02 & .04 & -.06 & .12 & .06 & .03 & -.002 \\
\hline Lower $(\mathrm{n}=37)$ & $.34 * *$ & .23 & $.33 * *$ & .20 & .25 & $.47 * *$ & .01 & .13 & .16 & $.42 * *$ \\
\hline
\end{tabular}

Among learners who were not familiar with writing a summary in English, some students could write a summary using strategies effectively, and others could not. However, the reason for the differences in the frequency of strategy use may be different depending on the performance levels. Table X shows their comments in the open-ended question which was asked after they completed the task of summary writing, and the comments presented in the Table $\mathrm{X}$ are the most common opinions of the whole.

As shown in the Tables IX and X, firstly, students in the high proficiency group reported that they did not use the strategies such as Q8 (You read while paying attention to the meaning of the words or phrases in the text) and Q4 (You read while confirming the understanding of the text) because they could comprehend the text without using them, and they wanted to start to write as soon as comprehending a text instead. On the other hand, among the students in the low proficiency group, some students who wrote a better summary reported that they used these strategies to comprehend the text completely before writing a summary, and others who did not write anything or copied from the source reported that they did not use these strategies because they did not have much motivation to complete the task. Thus, in the case of the students in the low proficiency group, the more they used the strategies of Q8 (You read while paying attention to the meaning of the words or phrases in the text) and Q4 (You read while confirming the understanding of the text), the higher score of performances they got even though they could not reach the same level as the students in the high proficiency group.

Secondly, in the case of writing strategy of Q23 (You wrote a summary in your own words after selecting some parts from the English text), in the low proficiency group, students used the strategy of Q23 (You wrote a summary in your own words after selecting some parts from the English text) obtained better score than those who did not use this strategy. Even though higher students in the low proficiency group could not write the summary as well as the students in the high proficiency group, they could obtain the better score than those who did not write anything or just copied from the source text (i.e., lower students in the low proficiency group) because lower students in the low proficiency 
group were evaluated as inappropriate summary writers. However, in the case of students in the high proficiency group, contrary to the students in the low proficiency group, students positively used the strategy of Q23 (You wrote a summary in your own words after selecting some parts from the English text) could not obtain better score than those who did not positively use the strategy. Actually, as shown in Table VIII, the mean scores of Language use is not prominently different between higher and lower students in the high proficiency group (e.g., Mean=3.32, S.D.=0.58 for the higher students in the high proficiency group; Mean=2.83, S.D.=0.64 for the lower students in the high proficiency group), therefore, it predicts that students in this level lose the score of Language Use if they actively paraphrase because they do not have enough knowledge of grammar and vocabulary to manipulate paraphrasing.

TABLE X.

RESPONSES OF THE OPEN-ENDED QUESTIONNAIRE TO ALL STUDENTS $(\mathrm{N}=74)$

\begin{tabular}{|c|c|c|}
\hline & High proficiency group $(n=37)$ & Low proficiency group $(n=37)$ \\
\hline Q8. & $\begin{array}{l}\text { Higher }(n=19) \\
\text { - I did not pay attention to the meaning of the words in the text } \\
\text { because I could understand the text. } \\
\text { Lower ( } n=18) \\
\text { - I did not have much time to pay attention to the meaning } \\
\text { of words in the text because I wanted to spend much } \\
\text { time to write. } \\
\text { - I read the text while guessing the meaning of new words } \\
\text { because I could not spend much time to read the text (I } \\
\text { wanted to move on the writing process). }\end{array}$ & $\begin{array}{l}\text { Higher }(n=19) \\
\text { - I tried to pay attention to the meaning of words in the text because } \\
\text { - I had to comprehend the text to write a summary. } \\
\text { Lower }(n=18) \\
\text { - I am not good at English, so I could not understand the text at all. } \\
\text { - I am sleepy. }\end{array}$ \\
\hline Q4. & $\begin{array}{l}\text { Higher }(n=19) \\
\text { - I did not need to use the strategy because I could comprehend } \\
\text { the text. } \\
\text { Lower }(n=18) \\
\text { - I did not have much time to confirm the understanding of the } \\
\text { text. } \\
\text { - I wanted to move on the writing process as soon as possible } \\
\text { because I am not good at writing. }\end{array}$ & $\begin{array}{l}\text { Higher }(n=19) \\
\text { - I used it because I needed to comprehend the text before writing } \\
\text { summary. } \\
\text { - I tried to read the text carefully to remember the content of the text for } \\
\text { summarizing the text. } \\
\text { Lower }(n=18) \\
\text { - I am not good at English, so I could not understand the text at all. } \\
\text { - I am sleepy. }\end{array}$ \\
\hline Q23. & $\begin{array}{l}\text { Higher }(n=19) \\
\text { - I tried to change the vocabularies basically because I } \\
\quad \text { could not reconstruct (paraphrase) the English structure. } \\
\text { Lower ( } n=18) \\
\text { - Of course, I positively used the strategy because I know that } \\
\text { paraphrasing is necessary for summary writing. } \\
\text { - I tried to paraphrase the text though I was not good at English } \\
\text { (especially, grammar). }\end{array}$ & $\begin{array}{l}\text { Higher }(n=19) \\
\text { - I tried to not copy from the original text, but paraphrase the text. } \\
\text { - I tried to change the vocabularies in the sentences of the text. } \\
\text { Lower }(n=18) \\
\text { - I am not good at English, so I could not understand the text at all. } \\
\text { - I am sleepy. }\end{array}$ \\
\hline Q30. & $\begin{array}{l}\text { Higher }(n=19) \\
\text { - I could not use the strategy because I did not have much time } \\
\text { to use it. (Time was too short to complete the task.) } \\
\text { Lower ( } n=18) \\
\text { - I compared my summary with original text to check } \\
\quad \text { whether or not I copied from the text. }\end{array}$ & $\begin{array}{l}\text { Higher }(n=19) \\
\text { - I compared my summary with original text to check my English. } \\
\text { - I compared my summary with original text to check my English } \\
\text { spellings. } \\
\text { Lower }(n=18) \\
\text { - I am not good at English, so I could not understand the text at all. } \\
\text { - I am sleepy. }\end{array}$ \\
\hline
\end{tabular}

Finally, students with higher scores in the high proficiency group did not use the strategy of Q30 (You compared the summary you wrote with the original text) even though the students with the middle score (i.e., lower students in the high proficiency group and higher students in the low proficiency group) did positively use it. Some higher students in the high proficiency group reported that they did not have much time to compare their produced summary with the original text. However, students who used the strategy reported that they needed to compare their summaries with the original text in order to correct their spelling/English grammar and even confirm if they did not copy from the source text.

\section{CONCLUSION AND IMPLICATION}

The primary objective of this study was to investigate the strategy reported using for writing a summary by students who were enrolled in a general academic course at National Technical College in Japan, of which general English level was deemed to ranges between beginner to intermediate among their peers in regular schools in Japan. In usual classes, they did not receive academic writing course such as paraphrasing or integration of reading/listening and writing, and they were unfamiliar with writing in English. All the students were asked to write a summary in English from the source text written in English, and they also answered the questionnaire on the strategies they used in the process of completing a summary. The study was carried out by dividing the students into two groups; higher and lower depending on their summary performances.

Findings from this study were that students with higher scores (i.e., those in the high proficiency group) and those with lower scores (i.e., those in the low proficiency group) tend to use the same strategies but the frequency of the strategy use was different, though previous studies about EFL/ESL summary writers' strategies (i.e., Anderson, 1991; Brown \& Day, 1983; Carrell, 1989; Cohen, 1994) reported that not only the types and the number of strategies they 
used but also the frequency of strategy use were different depending on their English proficiency. Therefore, these findings were partly the same as the indications of the previous studies. Given some strategies such as Q4 (You read while confirming the understanding of the text) and Q8 (You read while paying attention to the meaning of the words or phrases in the text), students with good scores in the high proficiency group used fewer strategies than those with good scores in the low proficiency group. In other words, higher students in the high proficiency group use these strategies as little as lower students in the low proficiency group, but the reasons why they did not use such strategies were different. The students with good performances in the high proficiency group could comprehend the text without using these strategies, while the students with poor performances in the low proficiency group did not use them because they did not have motivation enough to attempt to complete the task.

Other findings on writing strategies from this study were that the students who obtained higher scores did not positively use the strategy of Q23 (You wrote a summary in your own words after selecting some parts from the English text) because they may have tried to complete the task as well as possible. Therefore, they tried to change the vocabularies instead of reconstruct the structures because they knew they did not have enough knowledge of grammar to paraphrase without grammatical errors. Also, the participants in this study must have struggled to complete the task because writing a summary was an unfamiliar and complex task for them, and they probably could not afford to plan their time to complete the summary task and compare their produced summary with the original text (i.e., Q30. 'You compared the summary you wrote with the original text').

This study is a seminal work, and it raised more questions than settled. As a future research should be carefully conducted, the present author would like to suggest as follow. In order to observe the quality of summaries EFL students produced, the same environment on reading comprehension should be established, therefore, all students are required to comprehend the text before writing a summary. Students with low English proficiency in this study suffered from comprehending the text, but it is the premise for writing a summary from the text source. Kato (2018) suggested in her study that provision of L1 glossary to the target words in the text source is a prominently effective instruction for the students who were not familiar with writing summary, and she mentioned that the support has to be given to learners in a way in which they may be able to capitalize on it at the appropriate stage of writing a summary. To be sure, lower students in the low proficiency group in this study did not seem to have much motivation to comprehend the text for writing a summary, but if they were received some L1 glossary in their unfamiliar words, they might have tried to use some strategies for reading comprehension.

Furthermore, some educational implications were raised through the findings of the present study. First, the teachers teaching summary writing to the students with non-proficiency or who are unfamiliar with writing a summary require to instruct the students how to use particular routines (e.g., strategies, like taking notes efficiently while reading the text, and reduce the activity occurred a cognitive load by reading the text back and forth). Second, they also need to positively instruct the students how to paraphrase or use synonyms in English before starting to practice a summary.

\section{APPENDiX A. ORiginAl TEXT FOR SUMMARY}

\section{Racing as Equals}

Dog sledding is one of the toughest sports in the world. A driver stands on a sled* and guides a team of dogs that pulls the sled through the snow. Both the driver and the dogs must be very strong in order to compete. The most famous race is a 1,600-kilometer dog-sledding race in Alaska. In the past, most teams took nearly a month to finish. However, in recent years, teams have become faster. In fact, nowadays, the winners usually complete the race in just eight or nine days.

Dog sledding has traditionally been a men's sport. However, it is now becoming more popular with women. In 1974, only one woman completed the race. By 2015, though, about one-third of the drivers were women. Some people believe that more women are taking part because they have seen other women win the race. In 1985, Libby Riddles became the first woman to win, and Susan Butcher won four times between 1986 and 1990.

In fact, dog sledding is one of the few sports where women and men compete together. Interestingly, animals are a part of most of these sports. For example, horse riding is another sport where males and females compete together. Men and women also compete against each other in fishing tournaments. Some people believe that men and women should take part in more sports together in the future.

*sled: そり

\section{Notes:}

1) Do not bulleted.

2) Do not copy the text as it is.

3) Make it one-third length of the original text (approximately 110 words).

4) Write a summarized text in short and detail in order for readers who do not know the content of the text to understand it. 
(1) Main Idea Coverage

5. EXCELLENT: A response has complete coverage of main ideas.

4. VERY GOOD: A response has coverage of most main ideas.

3. GOOD: A response has moderate coverage of main ideas.

2. MODERATE: A response has some coverage of main ideas.

1. POOR: A response has coverage of very few ideas.

0. NO: A response has no coverage of main ideas.

(2) Integration

5. EXCELLENT: A response rearranges the order of the statements logically, displays excellent examples of integration and connectives, and demonstrates global interpretation of the source text.

4. VERY GOOD: A response rearranges the order of the statements logically, displays good examples of integration and connectives, and demonstrates global interpretation of the source text.

3. GOOD: A response rearranges the order of the statements logically, displays moderate examples of integration and connectives, and demonstrates global interpretation of the source text.

2. MODERATE: A response basically follows the order of source text with few cases of re-ordering and integration, and is not global in the interpretation of the source text.

1. POOR: A response follows the original order of the statements in the source text, shows rare instance of proper integration and connectives, and is not global in their interpretation of the source text.

0. NO: A response has no instances of integration or connectives at all.

(3) Language Use

5. EXCELLENT: A response displays consistent facility in the use of language, demonstrating syntactic variety, appropriate word choice; it is within the word limit as required.

4. VERY GOOD: A response displays facility in the use of language, demonstrating syntactic variety and range of vocabulary, though it will probably have occasional noticeable minor errors in structure, or word form that do not interfere with meaning; it is basically within the word limit.

3. GOOD: A response demonstrates inconsistent facility in sentence formation and word choice that may result in lack of clarity and occasionally obscure meaning; and/or it exceeds the word limit to a noticeable degree.

2. MODERATE: A response has a noticeably inappropriate choice of words or word forms, an accumulation of errors in sentence structure and/or usage; and/or it exceeds the word limit to a large degree.

1. POOR: A response has serious and frequent errors in sentence structure or usage, the text shows a lack of control of vocabulary and/or grammar; and/or it exceeds the word limit to a large degree.

0. NO: A response is totally incomprehensible due to language errors, or because the response is left blank.

(4) Source Use

5. EXCELLENT: A response is predominantly in the summarizers' own words and sentence structures, in addition to the accurate use of the information from the source text.

4. VERY GOOD: A response is mostly in the summarizers' own words and sentence structures, in addition to the accurate use of the information from the source text.

3. GOOD: A response is basically in the summarizers' own words and sentence structures, in addition to appropriate use of information from the source text.

2. MODERATE: A response has some use of the summarizers' own words and sentence structures, in addition to the adequate use of the information from the source text.

1. POOR: A response is predominately verbatim copying the source text.

0. NO: A response demonstrates completely verbatim copying from the source text.

\section{APPENDIX C. QUESTIONNAIRE}

\section{Directions:}

This questionnaire is to ask you what kind of strategy you used for completing summary writing. Please fill the corresponding number following choices in the blanks part on the right of the number of each item.

5. Always true of me

4. Usually true of me

3. Somewhat true of me

2. Usually not true of me

1. Never or Almost true of me

0 . I do not know.

Before-reading:

1.___ You understand the task of summary writing.

2. Y__ You understand the meaning of the text's title. 


\section{While-reading:}

3. Y__ You read while guessing the approximate meaning.

4. Y You read while confirming the understanding of the text.

5. __ You skipped an unintelligible part of English sentences.

6. Y__ You read while predicting the meaning of unknown words and phrases.

7. Y_ You used linguistic knowledge (such as morphological analysis) as a clue to infer the meaning of unknown words.

8. You read while paying attention to the meaning of the words or phrases in the text.

9. Even if you had not understood the contents of English sentences, you tried to infer and understand them from the context.

10. Y__ You took notes in English when you catch the point you want to write as a summary later.

11. Y_ You took notes in Japanese when you catch the point you want to write as a summary later.

12. If If you could not understand English sentences, you read them again.

13. Y_ You read while considering the knowledge of the text content you already had.

14. T_ To produce a summary later, you tried to read the text while searching for the most important part of the English text and underline them.

15. You concentrated on reading the English text without thinking about producing a summary later.

16. You read the English text while looking for the important part of each paragraph and underlining them.

17. You made a plan to produce a summary while reading the English text.

\section{After-reading:}

18. When you wrote a summary, you underlined or circled to identify the important part of the text.

19. After reading the English text, you made a plan to produce a summary.

20. To reconfirm the content of English text and to organize what to write, you drew to summarize them in diagrams and tables.

21. You summarized the text in Japanese in advance.

\section{While-writing:}

22. You copied the part of the text to be written in summary.

23. You wrote a summary in your own words after selecting some parts from the English text.

24. You translated the note summarized in Japanese into English.

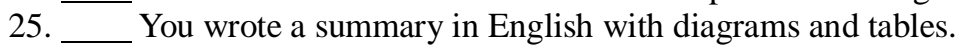

26. You wrote a summary in Japanese with diagrams and tables, and translated it into English.

27. You wrote summary while repeating to read the English text.

28. You wrote while looking over the specific phrases in the English text to be used for producing a summary.

29. You looked over the English text to catch some information to be used for producing a summary.

30. You compared the summary you wrote with the original text.

\section{Open-ended Questions:}

1. How did you feel to produce a summary?

2. What did you pay attention to while reading comprehension?

3. What did you pay attention to in the process of writing?

\section{REFERENCES}

[1] Anderson, N.J. (1991). Individual differences in strategy use in second language reading and testing. Modern Language Journal, 75, 460-472.

[2] Block, E. (1986). The comprehension strategies of second language readers. TESOL Quarterly 20, 463-494.

[3] Brown, A., \& Day, J. (1983). Macrorules for summarizing texts: The development of expertise. Journal of Verbal Learning and Verbal behavior, 22, 1-14.

[4] Carrell, P.L. (1989). Metacognitive awareness and second language reading. The Modern Language Journal, 73, $121-134$.

[5] Choy, S., \& Lee, M. (2012). Effects of teaching paraphrasing skills to students learning summary writing in ESL. Journal of Teaching and Learning, 8(2), 77-89.

[6] Cohen, A. (1994). English for academic purposes in Brazil: the use of summary tasks. In C. Hill, \& K. Parry (Eds.), From testing to assessment: English as an international language. (pp. 174-204). London: Longman.

[7] Glendinning, E. H., \& Holmstrom, B. (1992). Study reading: A course in reading skills for academic purposes. Cambridge: Cambridge University Press.

[8] Hirvela, A., \& Du, Q. (2013). Why am I paraphrasing?: Undergraduate ESL writers engagement with source-based academic writing and reading. Journal of English for Academic Purposes, 12: 87-98.

[9] Johns, A. M. (1985). Summary protocols of 'underprepared' and 'adept' university students: Replications and distortions of the original. Language Learning, 35(4), 495-517.

[10] Johns, A., \& Mayes, P. (1990). Analysis of summary protocols of university ESL students. Applied Linguistics, 11, $253-271$.

[11] Johnson, N. (1983). What Do You Do if You Can't Tell the Whole Story? The Development of Summarization Skills In Children's Language, Vol. 4, edited by KE. Nelson. Hillside, N.J.: Erlhaum.

[12] Kato, M. (2018). Providing Comprehension Clues in L1 to Japanese EFL Summary Writers: Do they help? International Journal of Applied Linguistics \& English Literature, 7(5). 
[13] Keck, C. (2006). The Use of Paraphrase in Summary Writing: A Comparison of L1 and L2 Writers. Journal of Second Language Writing, 15, (4), 261-278.

[14] Keck, C. (2010). How do university students attempt to avoid plagiarism? A grammatical analysis of undergraduate paraphrasing strategies. Writing \& Pedagogy, 2, 193-222 [Special issue on Plagiarism and the Academy].

[15] Kim, S. (2001). Characteristics of EFL Readers' Summary Writing: A Study with Korean University Students. Foreign Language Annals, 34(6). 569-581.

[16] Kintsch, W. \& Van Dijk, T. (1978). Toward a model of text comprehension and production. Psychological Review, 85: 363394.

[17] Kirkland, M. \& Saunders, M. (1991). Maximizing Student Performance in Summary Writing: Managing Cognitive Load. TESOL Quarterly, 25: 105-121.

[18] Koda, K. (2005). Insights into second language reading: A cross-linguistic approach. NY: Cambridge University Press.

[19] Langan, J. (1993). Ten steps to advancing college reading skills. Marlton, NJ: Townsend.

[20] Li, J. (2014). The role of reading and writing in summarization as an integrated task. Language Testing in Asia. 4(3).

[21] Li, J. (2016). Modeling the process of summary writing of Chinese learners of English as a foreign language. Irish Educational Studies, 35(1), 73-100.

[22] Phakiti, A. (2003a). A closer look at gender differences in strategy use in L2 reading. Language Learning, 53, 649-702.

[23] Polansky, M. (2011). Strategies for workplace learning used by entry-level physician assistants. Journal of Physician Assistant Education, 22(3), 43-50.

[24] Rinehart, S. D., \& Thomas, K.F. (1993). Summarization ability and text recall by novice studiers. Reading Research and Instruction, 32 (4), 24-32.

[25] Shi, L. (2004). Textual borrowing in second-language writing. Written Communication, 21,171-200.

[26] Shi, L. (2012). Rewriting and paraphrasing source texts in second language writing. Journal of Second Language Writing, 21, 134-148.

[27] Swales, J. (1981). Aspects of article introductions. Birmingham, UK: The University of Aston, language Studies Unit, 1981.

[28] Swales, J. (2000). Languages for specific purposes. Annual Review of Applied Linguistics 20, 59-76.

[29] van Dijk, T. A., \& Kintsch, W. (1983). Strategies of discourse comprehension. New York: Academic Press.

[30] Wichadee, S. (2013). Improving students' summary writing ability through collaboration: A comparison between online wiki group and conventional face-to-face group. The Turkish Online Journal of Educational Technology, 12(3), 107-116.

[31] Winograd, P. (1984). Strategic difficulties in summarizing texts. Reading Research Quarterly, 19, 404-425.

[32] Wohl, M. (1978). Techniques for writing composition. Rowley, Mass: Newbury House.

[33] Yang, L., \& Shi, L. (2003). Exploring Six MBA Students' Summary Writing by Introspection. Journal of English for Academic Purposes, 2, 165-192.

Makiko Kato was born in Aichi, Japan, and had taught English at junior and senior high schools in Aichi for eight years. She entered the graduate program of Linguistics at Tohoku University in Sendai, Japan, and she studied theoretical linguistics. She is now a Ph.D. candidate at Sophia University in Tokyo, Japan. She is also teaching English at universities in Tokyo, Japan. Her interest is exploring the complex skill of summarizing the text in English as a Foreign Language. 